\title{
HUBUNGAN PERILAKU KEBERSIHAN DIRI PADA ANAK YANG TERINFEKSI ENTEROBIUS VERMICULARIS DI SEKOLAH DASAR NEGERI RANCASARI DESA RANCAMANGGUNG KECAMATAN TANJUNGSIANG KABUPATEN SUBANG PROVINSI JAWA BARAT
}

\author{
Sumiati Bedah ${ }^{1)}$, Syahrial Harun ${ }^{1)}$, Yuni Astri Filmi ${ }^{1)}$ \\ ${ }^{1}$ Program Studi Analis Kesehatan, Fakultas Kesehatan, Universitas Mohammad Husni Thamrin \\ Correspondence author: Sumiati Bedah, sumiatibedah@yahoo.co.id, Jakarta, Indonesia
}

\begin{abstract}
ABSTRAK
Menurut hasil data dari World Health Organization (WHO) tahun 2013, lebih dari 1,5 miliar orang dari populasi dunia terinfeksi kecacingan nematoda usus. Infeksi tersebar luas di daerah tropis dan subtropis, dengan jumlah rerbesar di Sub-Sahara Afrika, Cina, dan Asia Timur. Salah satunya penyakit usus yang disebabkan oleh cacing Enterobiasis adalah salah satu yang disebabkan oleh Enterobius vermicularis. Tujuan dari penelitian ini adalah untuk mengetahui prevalensi infeksi enterobiasis dan hubungannya dengan kebersihan diri pada anak-anak Sekolah Dasar Negeri Rancasari Desa Rancamanggung Kecamatan Tanjungsiang Kabupaten Provinsi Jawa Barat. Pada penelitian ini menggunakan metode penelitian deskriptif analitik. Dengan metode pemeriksaan selopan tape. Hasil penelitian pada 72 sampel yang diperiksa didapatkan 10 (13,9\%) positif infeksi enterobiasis dan sempel negatif terdapat 62 anak $(86,1 \%)$. Analisis statistik dengan spss versi 23 pada uji Chi-square didapatkan hasil tidak adanya hubungan yang bermakna antara kebersihan diri dengan infeksi enterobiasis dikarenakan hasil $\mathrm{p}>0,05$.

Kesimpulan dari penelitian ini tidak ada hubungan yang bermakna antara kebersihan diri dengan infeksi enterobiasis, walaupun demikian disarankan kepada masyarakat tetap memperhatikan kebersihan diri dan kebersihan makanan agar terhindar dari penyakit infeksi kecacingan salah satunya enterobiasis.
\end{abstract}

Kata Kunci : Enterobius vermicularis, Enterobiasis, Perilaku Kebersihan Diri

\section{ABSTRACT}

\begin{abstract}
More than 1.5 billion people from the world's population are infected with intestinal nematode worms. Infections are widespread in tropical and subtropical regions, with the greatest number in Sub-Saharan Africa, China and East Asia. One of the intestinal diseases caused by worms, Enterobiasis is one caused by Enterobius vermicularis. The purpose of this study was to determine the prevalence of enterobiasis infection and its relationship with personal hygiene in Rancasari Elementary School children, Rancamanggung Village, Tanjungsiang District, West Java Province. In this study using a descriptive analytic research method. With the tape selopan inspection method. The results of the study on 72 samples examined found 10 (13.9\%) positive for enterobiasis infection and a negative sample of 62 children (86.1\%). Statistical analysis with SSS version 23 in the Chi-square test showed that there was no significant relationship between personal hygiene and enterobiasis infection because the results were $p>0.05$.

The conclusion of this study is that there is no significant relationship between personal hygiene and enterobiasis infection, although it is recommended that the public pay attention to personal hygiene and food hygiene in order to avoid worm infections, one of which is enterobiasis.
\end{abstract}

Keywords: Enterobius vermicularis, Enterobiasis, Personal Hygiene Behavior

Open Journal System (OJS): journal.thamrin.ac.id

http://journal.thamrin.ac.id/index.php/anakes/issue/view/36 


\section{PENDAHULUAN}

Menurut hasil data dari World Health Organization (WHO) tahun 2013, lebih dari 1,5 miliar orang dari populasi dunia terinfeksi kecacingan nematoda usus. Infeksi tersebar luas di daerah tropis dan subtropis, dengan jumlah rerbesar di Sub-Sahara Afrika, Cina, dan Asia Timur.

Infeksi kecacingan merupakan penyakit parasit yang endemik di Indonesia. Sebanyak 60-80\% penduduk Indonesia, terutama di daerah pedesaan menderita infeksi cacing terutama infeksi cacing perut. Faktor tingginya infeksi ini adalah letak geogerafik Indonesia di daerah tropik sehingga memungkinkan cacing perut dapat berkembang biak dengan baik (Sutanto I et al,2008).

Tubuh manusia yang merupakan hospes definitif dari penyakit cacingan yang di jumpai anak usia 4-12 tahun salah satunya adalah telur cacing Enterobius vermicularis atau sering di sebut dengan cacing kremi, beda halnya dengan telur cacing yang lain telur cacing Enterobius vermicularis ini hidup di lingkungan kotor dan hidup disuhu lembab, dan berkembang biak di suhu dingin contoh lainnya yaitu di sprei, mainan, dan lain-lain. Angka kejadian Enterobius vermicularis adalah 92\% terjadi pada anakanak Sekolah Dasar (Chai J-Y Yang SK,2015).

Angka kejadian tersebut dapat dilihat berdasarkan pola hidup dan juga asuhan orang tua. Cacing kremi adalah nematoda usus yang habitatnya di usus besar rectum. Cacing ini hampir luas penyebarannya di kalangan masyarakat, pada gambaran masyarakat mengenai cacing kremi umumnya terjadi, terutama pada anak-anak, dan penyakit parasit ini dapat menular kepada siapapun, namun yang paling sering terjadi pada anak-anak. Hal ini disebabkan karena mereka belum bisa menjaga pola hidup bersih dan sehat dan tubuhnya masih rentan terhadap penyakit. Pada hal ini yang dapat menyebabkan terjadinya infeksi Enterobius vermicularis pada anak-anak adalah dengan pola hidup sehari-hari yang sering membeli jajanan dengan sembarangan,tidak mencuci tangan sebelum makan atau tidak mencuci tangan setelah buang air besar, serta kurangnya menjaga kebersihan pakaian dan tempat tidur seperti jarangnya mengganti baju setelah aktivitas siang hari sebelum tidur dan jarang mencuci seprai. Dengan terjadinya suatu infeksi Enterobius vermicularis dapat dicegah dengan cara asupan dan pola hidup bersih (Sutanto I et al,2008). 
Peneliti tertarik untuk meneliti mengenai deteksi Enterobius vermicularis di Sekolah Dasar Negeri Rancasari yang berada di Kampung Patrol Menteng Desa Rancamanggung Kecamatan Tanjungsiang Kabupaten Subang, karena tempatnya terletak di daerah perkebunan dan beriklim tropik dengan suhu $12^{\circ} \mathrm{C}$ dan dengan keadaan sehari-harinya terlihat kurang nyaman. Selain lingkungan Sekolah Dasar terletak di daerah perkebunan juga dikaitkan dari sistem ekonomi yang rendah dan pendidikan atau pengetahuan orang tua yang kurang. Serta makanan dan minuman yang dijual di kantin atau lingkungan sekolah kurang di perhatikan kebersihannya dan anak-anak sekolah dasar kurang memperhatikan kebersihan tangan pada saat mengkonsumsi makanan atau minuman yang mereka beli. Maka memungkinkan potensi untuk terpapar adanya telur cacing Enterobius vermicularis yang kemungkinan bisa masuk dalam tubuh dan menginfeksi anak-anak sekolah dasar karena tidak adanya perhatian lebih dari orang tua terhadap kesehatan atau kebersihan anak.

\section{METODE}

Pada penelitian ini populasi yang digunakan adalah seluruh siswa di SDN Rancasari Kampung Patrol Menteng Desa Rancamanggung Kecamatan Tanjungsiang Kabupaten Subang.

Sampel untuk penelitian ini adalah seluruh siswa di SDN Rancasari Kampung Patrol Menteng Desa Rancamanggung Kecamatan Tanjungsiang Kabupaten Subang. Dari seluruh siswa yang berjumlah 100 orang, yang bersedia dijadikan responden sebanyak 72 orang. yang telah di berikan identitas atau kode disimpan pada wadah plastik yang berperekat. Sempel yang sudah siap di bawa lalu di periksa di Laboratorium Parasitologi Universitas MH Thamrin Jakarta Timur.

\section{HASIL DAN PEMBAHASAN}

SDN Rancasari terletak di kampung Patrol Menteng RT 08 RW 02 Desa Rancamanggung Kecamatan Tanjungsiang Kabupaten Subang Provinsi Jawa Barat merupakan wilayah yang terletak di daerah pegunungan bersuhu dingin sektiar $12^{\circ} \mathrm{C}$ sampai dengan $15^{\circ} \mathrm{C}$ pada suhu malam hari dan memiliki luas $2.100 \mathrm{~m}^{2}$. Menurut hasil pemeriksaan telur cacing Enterobius vermicularis dengan jumlah sampel 
sebanyak 72 dari bahan usap anus (anal swab) pada siswa SDN Rancasari Desa Rancamanggung Kecamatan Tanjungsiang Kabupaten Subang Provinsi Jawa Barat didapatkan hasil positif sebanyak 10 $(13,9 \%)$ anak dan hasil negatif sebanyak $62(86,1 \%)$ anak. Selengkapnya dapat dilihat pada Tabel 1 berikut :

Tabel 1.

Persentase Enterobius vermicularis pada anak SDN Rancasari Desa Rancamanggung Kecamatan Tanjungsiang Kabupaten Subang Provinsi Jawa Barat.

\begin{tabular}{ccc}
\hline Hasil pemeriksaan & Jumlah & Persentase (\%) \\
\hline Positif & 10 & $13,9 \%$ \\
\hline Negatif & 62 & $\mathbf{8 6 , 1 \%}$ \\
\hline Jumlah & 72 & $100 \%$ \\
\hline
\end{tabular}

( Sumber : Data Primer, 2019)

Berdasarkan hasil persentase yang telah didapatkan maka data dikelompokan berdasarkan usia dan jenis kelamin dan hubungannya dengan keberadaan Enterobius vermicularis pada siswa SDN Rancasari Desa Rancamanggung Kecamatan Tanjungsiang Kabupaten Subang Provinsi Jawa Barat dapat dilihat pada Tabel 2.

Tabel 2

Hubungan antara karakteristik (usia dan jenis kelamin) dengan Telur Enterobius vermicularis pada anak SDN Rancasari, Subang.

\begin{tabular}{lcccc}
\hline \multicolumn{4}{c}{ Hasil Pemeriksaan } \\
\hline Karakteristik responden & Positif & Negatif & Jumlah & Nilai P \\
\hline Usia & & & & \\
\hline 7 Tahun & $3(12,0 \%)$ & $22(88,0 \%)$ & 25 & 0,612 \\
8 Tahun & $3(25,0 \%)$ & $9(75,0 \%)$ & 12 & \\
9 Tahun & $3(15,0 \%)$ & $17(85,0 \%)$ & 20 & \\
10 Tahun & $1(6,7 \%)$ & $14(93,3 \%)$ & 15 & \\
\hline Jenis kelamin & & & & \\
\hline Laki-laki & $6(18,2 \%)$ & $27(81,8 \%)$ & 41 & 0,496 \\
Perempuan & $4(10,3 \%)$ & $35(89,7 \%)$ & 31 & \\
\hline
\end{tabular}

(Sumber : Data Primer,2019)

Selain berdasarkan usia dan jenis kelamin, data yang diperoleh juga dikelompokan berdasarkan kebersihan diri siswa untuk melihat adanya hubungan antara kebersihan diri dengan keberadaan telur Enterobius vermicularis pada siswa SDN Rancasari Desa Rancamanggung Kecamatan Tanjungsiang Kabupaten Subang Provinsi Jawa Barat setelah data didapatkan maka dilakukan uji statistik dengan uji Chi-square seperti pada Tabel 3. 
Tabel 3.

Hubungan antara Kebersihan Diri dengan Telur Enterobius vermicularis Pada Anak SDN Rancasari, Subang

\begin{tabular}{|c|c|c|c|c|}
\hline \multicolumn{5}{|c|}{ Hasil Pemeriksaan } \\
\hline Kebersihan diri & Positif & Negatif & Jumlah & Nilai $\mathbf{P}$ \\
\hline \multicolumn{5}{|l|}{ Mandi dalam 1 hari } \\
\hline a. 1 kali & $2(28,6 \%)$ & $5(71,4 \%)$ & 7 & 0,845 \\
\hline b. 2 kali & $4(8,7 \%)$ & $42(91,3 \%)$ & 46 & \\
\hline c. 3 kali & $4(21,1 \%)$ & $15(78,9 \%)$ & 19 & \\
\hline \multicolumn{5}{|c|}{ Pemotongan kuku kaki dan tangan } \\
\hline a. Sering & $10(15,9 \%)$ & $53(84,1 \%)$ & 63 & 0,343 \\
\hline b. Jarang & $0(0,0 \%)$ & $9(100,0 \%)$ & 9 & \\
\hline \multicolumn{5}{|c|}{ Cuci tangan sebelum makan } \\
\hline a. Selalu & $10(16,7 \%)$ & $50(83,3 \%)$ & 60 & 0,196 \\
\hline b. Jarang & $0(0,0 \%)$ & $12(100,0 \%)$ & 12 & \\
\hline \multicolumn{5}{|c|}{ Cuci tangan sesudah BAB } \\
\hline a. Selalu & $10(14,1 \%)$ & $61(85,9 \%)$ & 71 & 1,000 \\
\hline b. Tidak pernah & $0(0,0 \%)$ & $1(100,0 \%)$ & 1 & \\
\hline \multicolumn{5}{|l|}{ Kebersihan jajanan } \\
\hline a. Sering & $9(16,7 \%)$ & $45(83,3 \%)$ & 54 & 0,434 \\
\hline b. Jarang & $1(5,6 \%)$ & $17(94,4 \%)$ & 18 & \\
\hline \multicolumn{5}{|l|}{ Pencucian sprai } \\
\hline a. $\quad$ Selalu & $10(15,4 \%)$ & $55(84,6 \%)$ & 65 & 0,583 \\
\hline b. Jarang & $0(0,0 \%)$ & $7(100,0 \%)$ & 7 & \\
\hline \multicolumn{5}{|c|}{ Lama penggantian sprai } \\
\hline a. < 1 minggu & $2(13,3 \%)$ & $13(6,7 \%)$ & 15 & 0,714 \\
\hline b. 1 minggu & $5(12,5 \%)$ & $35(87,5 \%)$ & 40 & \\
\hline c. $>1$ minggu & $3(17,6 \%)$ & $14(82,4 \%)$ & 17 & \\
\hline \multicolumn{5}{|l|}{ Gatal dibagian anus } \\
\hline a. Sering & $2(50,0 \%)$ & $2(50,0 \%)$ & 4 & 0,077 \\
\hline b. Jarang & $4(14,8 \%)$ & $23(85,2 \%)$ & 27 & \\
\hline c. Tidak pernah & $4(9,3 \%)$ & $37(90,2 \%)$ & 41 & \\
\hline \multicolumn{5}{|l|}{ Susah tidur } \\
\hline a. Pernah & $6(20,7 \%)$ & $23(79,3 \%)$ & 29 & 0,187 \\
\hline b. Tidak pernah & $4(9,3 \%)$ & $39(90,7 \%)$ & 43 & \\
\hline \multicolumn{5}{|c|}{ Melakukan pemeriksaan } \\
\hline a. Pernah & $3(18,8 \%)$ & $13(81,3 \%)$ & 16 & 0,682 \\
\hline b. Tidak pernah & $7(12,5 \%)$ & $49(87,3 \%)$ & 56 & \\
\hline
\end{tabular}

(Sumber : Data Primer,2019)

Berdasarkan Tabel 2 dinyatakan bahwa hasil positif pada siswa usia 7 tahun adalah sebanyak $(12,0 \%)$, usia 8 tahun sebanyak (25,0\%), usia 9 tahun sebanyak $(15,0 \%)$ dan usia 10 didapat sebanyak $(6,7 \%)$. Berdasarkan uji statistik didapatkan hasil nilai $\mathrm{p}=0,612(\mathrm{p}>0,05)$ sehingga dianyatakan tidak ada hubungan antara perbedaan usia dengan angka enterobiasis. Sedangkan berdasarkan jenis kelamin, didapatkan hasil positif pada siswa laki-laki adalah sebanyak $(18,2 \%)$ dan perempuan sebanyak 
$(10,3 \%)$ dengan nilai $p=0,496(p>0,05)$ sehingga dinyatakan tidak ada hubungan antara jenis kelamin dengan infeksi enterobiasis.

Berdasarkan Tabel 3, didapatkan hasil positif dengan kebiasaan mandi 1 kali sehari adalah sebanyak 2 anak ( 28,6\%), kebiasaan mandi 2 kali sehari sebanyak 4 anak (8,7\%) dan kebiasaan mandi 3 kali sehari 4 anak $(21,1 \%)$ dengan nilai $p=0,845(p>0,05)$ maka tidak ada hubungan antara kebiasaan mandi dalam 1 hari dengan infeksi enterobiasis.

Berdasarkan frekuensi memotong kuku didapatkan hasil positif yaitu anak yang sering memotong kuku sebanyak $(15,9 \%)$ dan jarang memotong kuku sebanyak $(0,00 \%)$ dengan nilai $\mathrm{p}=0,343(\mathrm{p}>0,05)$ maka tidak ada hubungan antara frekuensi memotong kuku dengan infeksi enterobiasis.

Hasil pemeriksaan enterobiasis berdasarkan hubungan kebersihan diri yaitu kebiasaan mencuci tangan sebelum makan, didapatkan hasil positif pada anak yang selalu mencuci tangan sebanyak $(16,7 \%)$ dan anak yang jarang mencuci tangan sebelum makan sebanyak $(0,00 \%)$ dengan nilai $p=0,196(p>0,05)$ maka dinyatakan tidak ada hubungan antara mencuci tangan sebelum makan dengan infeksi enterobiasis.

Hasil pemeriksaan enterobiasis berdasarkan kebiasaan mencuci tangan sesudah Buang Air Besar (BAB) didapatkan hasil positif pada anak yang selalu mencuci tangan setelah BAB adalah sebesar $(14,1 \%)$ dan yang tidak pernah mencuci tangan setelah $\mathrm{BAB}$ sebesar $(0,00 \%)$ dengan nilai $\mathrm{p}=1,000$ $(\mathrm{p}>0,05)$ maka tidak ada hubungan antara mencuci tangan sesudah BAB dengan infeksi enterobiasis.

Hasil pemeriksaan enterobiasis berdasarkan kebiasaan memperhatikan jajanan, didapatkan hasil positif pada anak yang sering memperhatikan kebersihan jajanan adalah sebesar $9(16,7 \%)$ anak dan pada anak yang jarang memperhatikan kebersihan jajanan sebanyak $(5,6 \%)$ dengan nilai $\mathrm{p}=0,434(\mathrm{p}>0,05)$ maka dinyatakan tidak ada hubungan antara kebersihan jajanan dengan infeksi enterobiasis.

Hasil pemeriksaan enterobiasis berdasarkan hubungan kebersihan diri yaitu kebiasaan pencucian sprei, didapatkan hasil positif pada siswa yang selalu melakukan pencucian sprei sebanyak 10 anak ( $15,4 \%)$ dan yang jarang sebanyak $0(0,00 \%)$ dengan nilai $\mathrm{p}=0,583(\mathrm{p}>0,05)$ sehingga dinyatakan tidak ada hubungan antara kebiasaan mencuci sprei dengan infeksi enterobiasis.

Open Journal System (OJS): journal.thamrin.ac.id 
Hasil pemeriksaan enterobiasis berdasarkan hubungan kebersihan diri yaitu lama penggantian sprei, didapatkan hasil positif pada kebiasaan mengganti sprei $<1$ minggu sebesar $(13,3 \%), 1$ minggu sebanyak $(12,5 \%)$ dan $>1$ minggu sebanyak $(17,6 \%)$ dengan nilai $\mathrm{p}=0,714(\mathrm{p}>0,05)$ maka tidak ada hubungan antara lama penggantian sprai dengan infeksi enterobiasis.

Hasil pemeriksaan enterobiasis didapatkan hasil positif pada anak yang sering mengalami gatal pada bagian anus di malam adalah sebesar (50,0\%), anak yang jarang mengalami gatal sebesar $(14,8 \%)$ dan tidak pernah mengalami gatal sebnyak $(9,8 \%)$ dengan nilai $\mathrm{p}=0,077(\mathrm{p}>0,05)$ maka tidak ada hubungan antara gatal dibagian anus pada malam hari dengan infeksi enterobiasis.

Hasil pemeriksaan enterobiasis berdasarkan kebiasaan anak yang susah tidur di malam hari, didapatkan hasil positif adalah sebesar (20,7\%), anak yang tidak pernah mengalami susah tidur sebanyak $(9,3 \%)$ dengan nilai $\mathrm{p}=0,187(\mathrm{p}>0,05)$ maka tidak ada hubungan antara kebiasaan susah tidur pada malam hari dengan infeksi enterobiasis.

Hasil pemeriksaan enterobiasis berdasarkan kebiasaan melakukan pemeriksaan, didapatkan hasil positif pada anak yang pernah melakukan pemeriksaan adalah sebanyak $(18,8 \%)$ sedangkan anak yang tidak pernah melakukan pemeriksaan sebanyak $(12,5 \%)$ dengan nilai $\mathrm{p}=0,682(\mathrm{p}>0,05)$ maka tidak ada hubungan antara melakukan pemeriksaan dengan infeksi enterobiasis.

Berdasarkan hasil pemeriksaan yang dilakukan terhadap 72 siswa SDN Rancasari Desa Rancamanggung Kecamatan Tanjungsiang Kabupaten Subang Provinsi Jawa Barat didapatkan angka enterobiasis sebesar 13,9\% (10 orang anak). Penelitian ini lebih tinggi dibandingkan dengan penelitian Elen Pebriani dkk (2019) pada 14 anak usia 4-12 tahun di panti Asuhan Padang yang hasilnya 64,3\% (9 anak positif). Perbedaan tersebut bisa disebabkan oleh lingkungan tempat tinggal responden.

Berdasarkan karakteristik usia ternyata tidak terdapat hubungan yang bermakna antara usia dengan infeksi enterobiasis dan berdasarkan karakteristik jenis kelamin tidak terdapat hubungan yang bermakna antara jenis kelamin dengan infeksi enterobiasis, maka dapat disimpulkan bahwa infeksi enterobiasis yang disebabkan oleh telur Enterobius vermicularis dapat terjadi pada semua orang tanpa memandang usia dan jenis kelamin. 
Menurut hasil uji statistik dengan Chi-square didapatkan hasil yang menunjukan bahwa tidak ada hubungan antara kebersihan diri dengan infeksi enterobiasis, hal ini dikarenakan kemungkinan pada saat pengisian kuesioner pernyataan yang dituliskan oleh responden tidak sesuai dengan kondisi yang sebenarnya atau diakibatkan karena faktor lain yang memungkinkan telur Enterobius vermicularis dapat hidup.

\section{SIMPULAN}

Angka infeksi enterobiasis pada anak-anak di SDN Rancasari Desa Rancamanggung Kecamatan Tanjungsiang Kabupaten Subang Provinsi Jawa Barat berjumlah (13,9\%) dari 72 sempel yang diperiksa. Tidak ada hubungan antara karakteristik responden yaitu usia dan jenis kelamin dengan angka enterobiasis. komponen kebersihan diri yang diambil dari data kuesioner yang di isi responden yaitu tentang mandi dalam satu hari, kebersihan kuku, kebiasaan mencuci tangan sebelum makan, mencuci tangan sesudah $\mathrm{BAB}$, kebersihan jajanan, pencucian sprai, lama penggantian sprai, gatal dibagian anus pada malam hari, mengalami susah tidur dan melakukan pemeriksaan tidak ada satupun hasil uji statistik dengan Chi-square yang menunjukan hasil terdapat hubungan antaran kebiasaan tersebut dengan infeksi enterobiasis.

\section{UCAPAN TERIMA KASIH}

Penulis mengucapkan terima kasih kepada Prodi D III Analis Kesehatan Universitas MH Thamrin berperan serta dalam penelitian ini.

\section{DAFTAR PUSTAKA}

1. Abidin, S, A, N, Enterobius vermicularis, Dalam Parasitologi kedokteran, Oleh Inge Susanto, Isn Suhariah Ismid, Pudji K.Sjaripudin, edisi 4, Jakarta, 2008

2. Chai J-Y Yang SK, Kim JW, Choi S-L, Song G-Y, Jung B-K, et al. High prevalence on Enterobius vermiculari Infection among school children in there twinship around Yangon, Myanmar. Journal parasitology. 2015

3. Dep. Kes RI, 2006. Keputusan Menteri Kesehatan Republik Indonesia NO.424/MENKES/SK/VI/2006 Tentang Pedoman Pengendalian Cacingan,Jakarta

4. Gandahusada et al. 2004. Kejadian Enterobiasis. Jakarta Selatan : Vol. 2, No. Hal 12-22

5. Imran. D. Dkk, 2013. Higienitas kuku tangan dan infestasi Enterobius vermicularis. Kalimantan : Vol 4, No. 2 : Hal 102-108. 
6. Notoatmodjo.S, 2007. Kesehatan Masyarakat Ilmu dan Seni, Jakarta: Rineka Cipta.

7. Sutanto I et al.2008. Parasitologi Kedokteran, Jakarta: Fakultas Kedokteran Universitas Indonesia

8. Widodo. H, 2013. Parasitologi Kedokteran, Jogjakarta: D-MEDIKA.

9. Widyastuti R. 2006. Parasitologi, Cetakan Keempat, Jakarta: Universitas Terbuka

10. World Health Organization. 2013, Soil-transmitted helmin infections.

http://www.who.int/mediacentre/factsheets/fs366/en/, diakses 25-7-2019. 